\title{
Consumption of Polyphenols in Coffee and Green Tea Alleviates Skin Photoaging in Healthy Japanese Women
}

This article was published in the following Dove Press journal: Clinical, Cosmetic and Investigational Dermatology

\author{
Yoichi Fukushima $\mathbb{D D}^{1}$ \\ Yoshinari Takahashi ${ }^{2}$ \\ Yoshimi Kishimoto $\mathbb{D D}^{3}$ \\ Chie Taguchi ${ }^{3}$ \\ Norie Suzuki ${ }^{3}$ \\ Mihoko Yokoyama (iD ${ }^{4}$ \\ Kazuo Kondo 3,5 \\ 'Wellness Communications Section, \\ Nestlé Japan Ltd., Tokyo, Japan; ${ }^{2}$ Inary \\ Corp., Tokyo, Japan; ${ }^{3}$ Endowed Research \\ Department "Food for Health", \\ Ochanomizu University, Tokyo, Japan \\ ${ }^{4}$ Yokoyama Skin Clinic, Tokyo, Japan; \\ ${ }^{5}$ Institute of Life Innovations Studies, \\ Toyo University, Gunma, Japan
}

Correspondence: Yoichi Fukushima Wellness Communications Section, Nestlé Japan Ltd., Tennoz Square, 2-2-20 Higashi-Shinagawa, Shinagawa-ku, Tokyo 140-0002, Japan

Tel +8I 357696299

Fax +81 357696291

Email yoichi.fukushima@jp.nestle.com
Purpose: Hyperpigmentation of the skin can occur at any age depending on etiological factors but its intensity increases during adolescence in Japanese females and gradually develops further in adults. The purpose of this study was to characterize factors that influence skin hyperpigmentation, including age, skin type and dietary polyphenol sources.

Patients and Methods: A cross-sectional survey of healthy Japanese women aged from 30 to 60 years $(\mathrm{n}=244)$ was conducted using food and environmental questionnaires and a VISIA ${ }^{\mathrm{TM}}$ facial photoimage analyzer.

Results: UV Pigmented Spot (PS) scores correlated negatively with the consumption of total polyphenols (TPs) $(\mathrm{R}=-0.224, \mathrm{p}<0.001)$ and the rate of hyperpigmented spot development (PS score/age after 18 years of age) was suppressed by the consumption of TPs. This trend was independent of the melanin index and the skin type, which indicates the ability of the skin to tan after sun exposure. Consumption of coffee, the largest source of TPs, suppressed the PS score $(p<0.001)$. Consumption of green tea, the second largest source of TPs, also suppressed the PS score, which was weaker than coffee but was statistically significant $(p=0.029)$. The PS score was suppressed the most in subjects with both a high consumption of coffee and green tea.

Conclusion: Higher consumption of TPs may be beneficial to alleviate photoaging of the skin, and coffee as well as green tea contribute to suppress skin hyperpigmentation through adding large amounts of TPs in the diet.

Keywords: coffee, green tea, polyphenol, photoaging, skin hyperpigmentation

\section{Introduction}

Sunlight, especially its ultraviolet (UV) light component, is the major factor that causes skin photoaging, which results in facial hyperpigmentation and wrinkle formation ${ }^{1} \mathrm{UV}$ light leads to collagen degradation and dysregulation of extracellular matrix homeostasis, and induces extensive skin damage through direct DNA damage, the production of reactive oxygen species (ROS), which cause lipid and protein peroxidation, and immune dysregulation that results in cell dysfunction and death. ${ }^{2}$ DNA damage caused directly by UV light and ROS generated by UV exposure may result in defective DNA repair and gene mutations. ${ }^{3}$ In vivo and in vitro studies have shown that oxidative stress and DNA damage in the skin caused by UV exposure are alleviated by the intake of antioxidants including vitamins, carotenoids and polyphenols. ${ }^{4}$ Therefore, photoaging of the skin could be modified by changing environmental and/or lifestyle factors including a diet with antioxidants. 
Recently, photoimaging technology has advanced significantly and non-invasive image analysis of hyperpigmented spots can now be used to analyze the photoaging status. ${ }^{5-7}$ In a previous study, we conducted a pilot crosssectional survey to determine how factors and nutrients in the diet influence the facial skin status using non-invasive skin analysis. ${ }^{6}$ That study demonstrated that subjects with high levels of coffee polyphenol consumption had lower levels of skin hyperpigmentation measured according to a VISIA ${ }^{\mathrm{TM}}$ UV Pigmented Spot (PS) score using a digital imaging technique. ${ }^{7}$ Coffee is the largest source of polyphenols in the Japanese diet and supplies a large amount of antioxidants in daily life. ${ }^{8,9}$

We have accumulated a basic knowledge about facial hyperpigmented spots and factors that influence them. ${ }^{10}$ Japanese women are well aware of the harmful effects of UV exposure and most of them use sun protection every day. Their previous sun exposure times were usually very short showing that the UV exposure time was not an influential factor in the PS score. Hyperpigmented spots typically appear initially in Japanese women around 18 years of age and their PS scores remarkably increase in their $20 \mathrm{~s}$ and then gradually increase further with age. Not only coffee polyphenol consumption but also age and genetic factors are significant influential factors in the PS score. The skin type is genetically determined by melanin formation after sun exposure and was identified as an independent strong influential factor in the PS score. Subjects with skin type I, one of the three grades of Japanese skin type (JST), whose melanin formation is genetically lower, showed higher PS scores. ${ }^{11}$

To further understand the influence of consuming polyphenols from coffee and from other sources, especially green tea (the second largest source of polyphenols in the Japanese diet), on skin conditions, we conducted an additional cross-sectional study to explore the influence of polyphenol consumption as well as genetic and environmental factors on facial skin hyperpigmentation in healthy Japanese women.

\section{Materials and Methods Study Design and Subjects}

This cross-sectional survey was conducted in accordance with the principles of the Declaration of Helsinki. This study was approved by the Shirogane EXE Clinic Ethics Committee, and all subjects provided written informed consent for their data to be used in the study. As described in our previous study, ${ }^{6}$ we recruited 131 subjects in the summer, and 113 subjects were newly added in the winter for this expanded study. Briefly, we collected subjects using an internet website of a contract research organization. Inclusion factors were healthy, non-smoking Japanese women, aged 30-60 years, and exclusion factors were subjects who had chronic diseases, who were taking medications, who had skin diseases or skin complaints (e.g. nevus, melasma and macules) or who had undergone artificial treatments such as chemical peeling, laser and/or light treatment, and injection of hyaluronic acid. We also excluded pregnant or lactating women, as well as subjects who had regular activities that potentially exposed them to sunburns, such as tennis, golf, body boarding, skiing, snowboarding (at least once a month), or outdoor activities in the summer, including climbing mountains and sea bathing (at least once a year) every year after 25 years of age. Subjects were also excluded who intentionally suntanned without a sunscreen, e.g. sea bathing, swimming in an outdoor pool or attending an outdoor athletic festival. The profile of the subjects in this study is shown in Table 1.

\section{Non-Invasive Measurement of Skin Conditions}

Skin condition measurements were conducted under the control of a physician. After washing her face, each subject was completely sedentary for $20 \mathrm{mins}$ in an environmentally controlled room at $22 \pm 1{ }^{\circ} \mathrm{C}$ and $50 \pm 10 \%$ relative humidity. PS scores and PS counts were measured using a VISIA ${ }^{\mathrm{TM}}$ Evolution facial image analysis system (Canfield Inc., Fairfield, NJ, USA). Examples of UV photos and PS scores are shown in Figure 1. The PS score/count (PS score divided by the PS count) was also calculated as an indicator of the average area of pigmented spots. The PS score divided by the number of years after becoming 18 years old is expressed as the rate of UV pigmented spot development. Skin color is expressed as $\mathrm{L}^{*}$ (lightness) value and the melanin index measured using a CM-2600d spectrophotometer (Konica-Minolta, Tokyo, Japan).

\section{Questionnaires on Lifestyle, Diet and Environmental Conditions}

A food questionnaire was conducted using a brief, self-administered Diet History Questionnaire (BDHQ) to calculate energy and nutritional intake, and alcohol consumption. ${ }^{12}$ The lifestyle of each subject, including their smoking and sun exposure habits, and actions geared towards any usual 
Table I Profile of the Subjects and Their Consumption of TPs

\begin{tabular}{|c|c|c|c|c|}
\hline \multirow[t]{2}{*}{ Number of Subjects } & & Summer & Winter & Total \\
\hline & & $|3|$ & 113 & 244 \\
\hline Age & Years & $44.4 \pm 8.0$ & $48.7 \pm 5.3$ & $46.4 \pm 7.2$ \\
\hline Body weight & kg & $51.8 \pm 6.5$ & $50.9 \pm 6.1$ & $51.4 \pm 6.3$ \\
\hline BMI & $\mathrm{kg} / \mathrm{m}^{2}$ & $20.8 \pm 2.2$ & $20.6 \pm 2.1$ & $20.7 \pm 2.2$ \\
\hline Energy consumption & $\mathrm{kcal} / \mathrm{day}$ & $1649 \pm 48 \mid$ & $1552 \pm 479$ & $1604 \pm 482$ \\
\hline Exercise & METs - h/week & $6.2 \pm 15.2$ & $3.7 \pm 9.7$ & $5.1 \pm 13.0$ \\
\hline Total polyphenol consumption & $\mathrm{mg} /$ day & $1279 \pm 864$ & || $63 \pm 78 \mid$ & $1225 \pm 827$ \\
\hline Beverage consumption & $\mathrm{mL} /$ day & $1566 \pm 783$ & $1160 \pm 665$ & $1378 \pm 757$ \\
\hline Coffee consumption & $\mathrm{mL} /$ day & $334 \pm 356$ & $319 \pm 347$ & $327 \pm 351$ \\
\hline Alcohol consumption & g/day & $2.7 \pm 5.2$ & $3.0 \pm 5.2$ & $2.8 \pm 5.2$ \\
\hline Ex-smoker & $N(\%)$ & $25(19.1 \%)$ & $0(0.0 \%)$ & $25(10.2 \%)$ \\
\hline \multicolumn{5}{|l|}{ Usage for UV protection } \\
\hline Sunscreen/Sun protection cosmetics & $\mathrm{N}(\%)$ & $126(96.2 \%)$ & $100(88.5 \%)$ & $226(92.6 \%)$ \\
\hline Sunshade or hat/cap & $N(\%)$ & $108(82.4 \%)$ & $74(65.5 \%)$ & $182(74.6 \%)$ \\
\hline Long sleeves & $N(\%)$ & $28(21.4 \%)$ & $34(30.1 \%)$ & $62(25.4 \%)$ \\
\hline \multicolumn{5}{|l|}{ Activity with sun exposure in the past } \\
\hline Outdoor sports ${ }^{\mathrm{a}}$ & $N(\%)$ & $12(9.2 \%)$ & $8(7.1 \%)$ & $20(8.2 \%)$ \\
\hline Outdoor activities in the summer ${ }^{b}$ & $\mathrm{~N}(\%)$ & $13(9.9 \%)$ & $4(3.5 \%)$ & $17(7.0 \%)$ \\
\hline
\end{tabular}

Notes: Mean \pm SD. ${ }^{a}$ Number of subjects who did the outdoor sports including tennis, golf, bodyboarding, snowboarding and ski at least 5 years before. ${ }^{b}$ Number of subjects who did outdoor activities in the summer including mountain climbing and sea bathing once in a few years.

Abbreviation: MET, metabolic equivalents.

sun protection were recorded using the questionnaire. The exercise level of each subject was expressed as metabolic equivalents (METs) calculated by information from the same questionnaire. ${ }^{13}$ The consumption of foods and beverages containing polyphenols was recorded through questionnaires aimed at calculating polyphenol intake. ${ }^{8}$ The consumption of total polyphenols (TPs) was estimated using the consumption data of food and beverage items in this survey and the polyphenol content database developed for Japanese foods and beverages, whose TP contents were holistically measured using a modified Folin Ciocalteu method. ${ }^{8}$ JSTs were classified based on questionnaires as Skin Type I reddens in response to UV exposure but unlikely to suntan (lower melanin producer), Type II modestly reddens in response to UV but able to suntan (average melanin producer), and Type III unlikely to redden or sunburn in response to UV exposure but easily suntans (higher melanin producer). ${ }^{11}$

\section{Data Analysis}

Numerical data are presented as means \pm SD. Subject groups were divided based on arbitrary cut-off points, such as median or tertile. Correlations among survey items were evaluated by the partial correlation coefficient based on the product-moment Pearson's correlation coefficient using the control variable as age, whereas age alone and the combination of other factors such as BMI, energy intake, alcohol consumption and skin type delivered similar results on the partial correlations when they were used

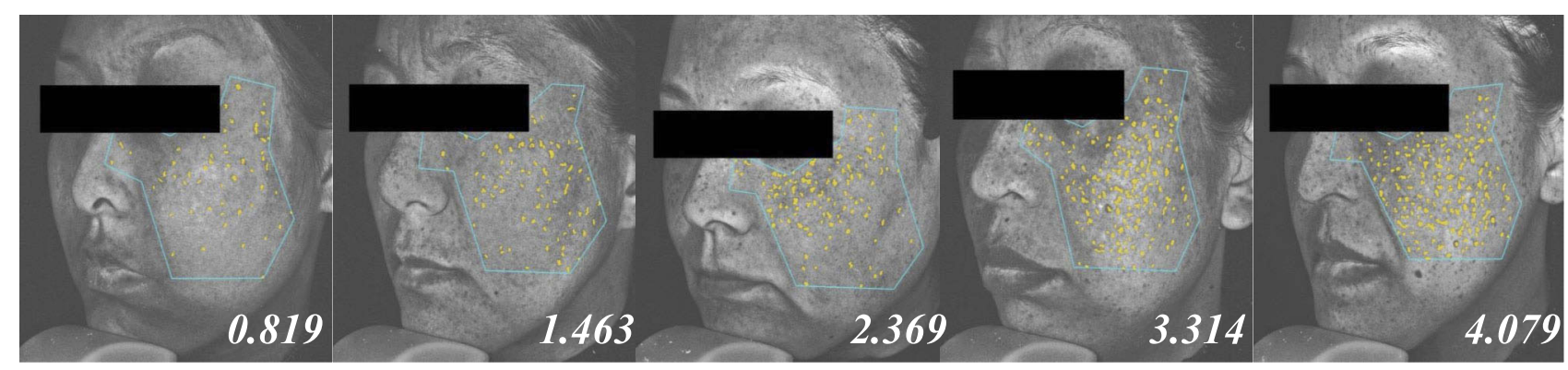

Figure I Examples of VISIA UV photoimages and UV Pigmented Spot scores. Images of five subjects in the study; the number at the bottom of each image is the PS score. 
Table 2 Partial Correlations Between the Consumption of TPs and UV Pigmented Spot (PS) Score

\begin{tabular}{|l|l|l|l|l|l|l|}
\hline & \multicolumn{2}{|l|}{$\begin{array}{l}\text { Summer } \\
(\mathbf{n}=131)\end{array}$} & \multicolumn{2}{l|}{$\begin{array}{l}\text { Winter } \\
(\mathbf{n}=113)\end{array}$} & \multicolumn{2}{l|}{ Total (n=244) } \\
\hline Total polyphenol vs. & $R$ & $P$ & $R$ & $P$ & $R$ & $P$ \\
PS score & -0.218 & 0.013 & -0.216 & 0.022 & -0.224 & $<0.001$ \\
PS count & -0.190 & 0.031 & -0.192 & 0.043 & -0.196 & 0.002 \\
PS score/count & -0.211 & 0.016 & -0.188 & 0.048 & -0.212 & 0.001 \\
\hline
\end{tabular}

Note: Control variable: age

as the control variable. Comparisons among groups were first analyzed using analysis of variance (ANOVA); then, Dunnett's test for multiple comparisons, or were directly analyzed using Welch's $t$-test between two groups. IBM ${ }^{\circledR}$ SPSS $^{\circledR}$ Statistics 19 (SPSS Japan Inc., Tokyo, Japan) was used and a p-value $<0.05$ is considered as significant.

\section{Results}

The VISIA ${ }^{\mathrm{TM}}$ UV Pigment Spot (PS) score had a negative partial correlation with the consumption of TPs in both surveys conducted in the summer and in the winter at $R=-0.218$ $(\mathrm{p}=0.013)$ and $\mathrm{R}=-0.216(\mathrm{p}=0.022)$, respectively (Table 2$)$, and we combined those two survey results for the following analysis. The consumption of TPs had negative partial correlations not only against the PS score $(\mathrm{R}=-0.224, \mathrm{p}<0.001)$ but also against both the PS count, an indicator of the number of pigmented spots $(\mathrm{R}=-0.196, \mathrm{p}=0.002)$, and the PS score/ count, an indicator of the average area of pigmented spots $(\mathrm{R}=-0.212, \mathrm{p}=0.001)$ (Table 2$)$. The PS score per age after each subject became 18 years-old, which estimates the rate of hyperpigmented spot development, was suppressed by the consumption of TPs, and its rate in the highest tertile TP group was significantly lower in the rate of hyperpigmented spot development ( $\mathrm{p}=0.001$ ) (Figure 2).

Skin type was a significant influential factor in the PS score, and subjects with Skin Type III, who have a higher production of melanin after UV exposure, showed a significantly lower PS score while subjects with Skin Type I, who have a lower production of melanin after UV exposure, showed the highest PS score ( $<<0.001$, Table 3 ). For each skin type, subjects with a higher consumption of TPs ( $\geq 1064 \mathrm{mg} /$ day) tended to show lower PS scores. The PS
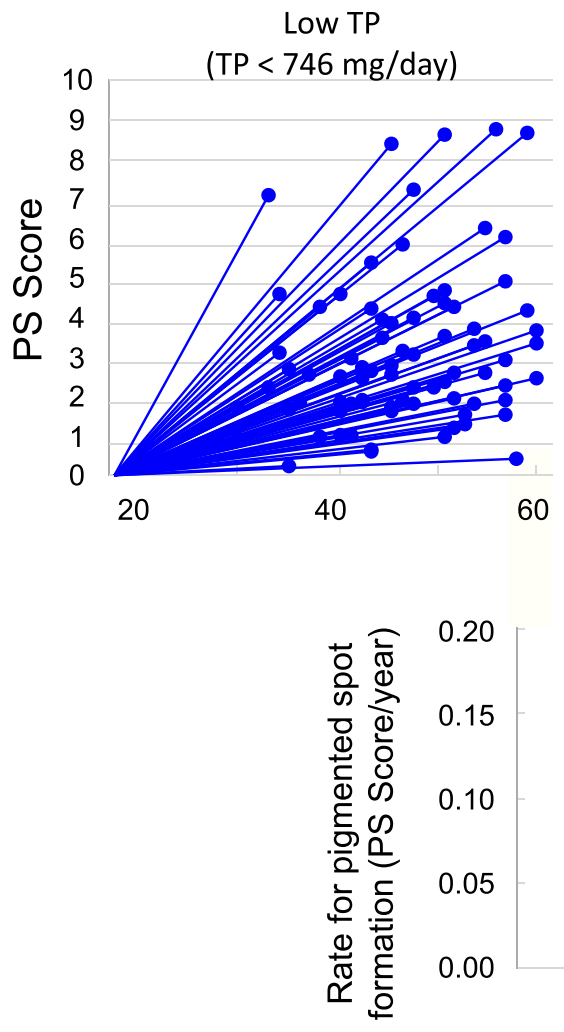

Middle TP

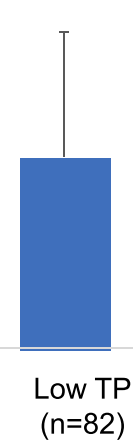

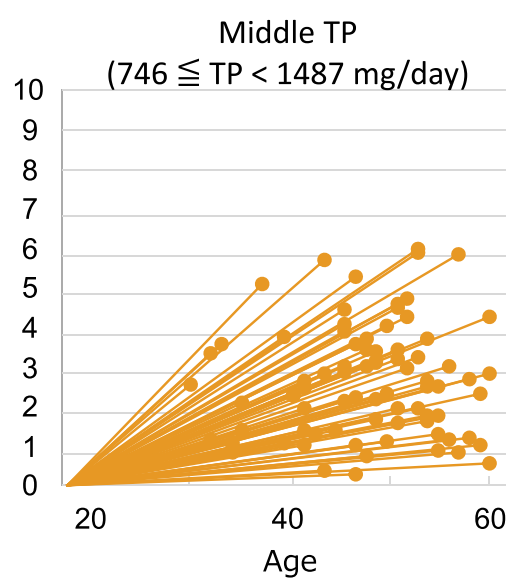

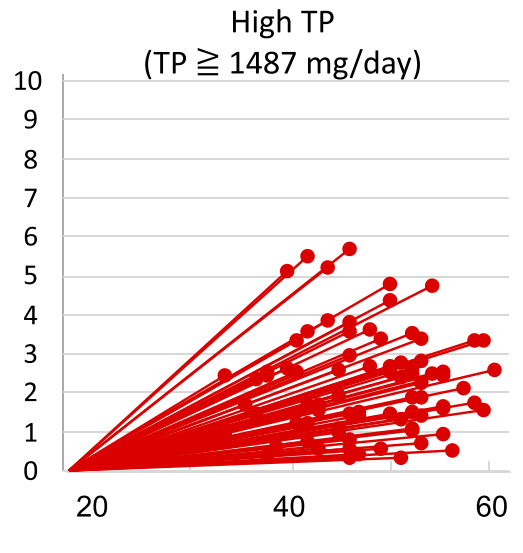

Mean \pm SD

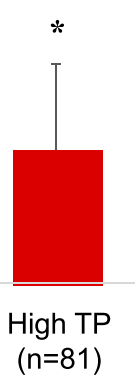

TP consumption

Figure 2 Distribution of UV Pigmented Spot scores and age of subjects in tertile groups divided by TP consumption, and UV Pigmented Spot development rate (PS score per year after reaching 18 years of age) and consumption of TPs. ANOVA $p$-value was $p=0.002 ;{ }^{*} p=0.001$ compared with the low TP consumption group. 
Table 3 PS Scores in Low and High TP Groups According to Skin Type, Skin Color and Melanin Index

\begin{tabular}{|c|c|c|c|c|c|c|c|c|}
\hline & & \multicolumn{2}{|c|}{ All Subjects } & \multicolumn{2}{|c|}{ Low TP } & \multicolumn{2}{|c|}{ High TP } & \multirow[t]{2}{*}{ p-value ${ }^{a}$} \\
\hline & & $\mathbf{n}$ & PS Score & $\mathbf{n}$ & PS Score & $\mathbf{n}$ & PS Score & \\
\hline Skin type & $\begin{array}{c}\text { I } \\
\text { II } \\
\text { III }\end{array}$ & $\begin{array}{l}65 \\
136 \\
43\end{array}$ & $\begin{array}{l}3.12 \pm 1.64 \\
2.74 \pm 1.6 I \\
1.56 \pm 1.08^{b} \\
p<0.001\end{array}$ & $\begin{array}{l}36 \\
72 \\
14\end{array}$ & $\begin{array}{l}3.44 \pm 1.89 \\
2.88 \pm 1.78 \\
I .62 \pm 1.0 I^{c} \\
P=0.005\end{array}$ & $\begin{array}{l}29 \\
64 \\
29\end{array}$ & $\begin{array}{l}2.72 \pm 1.18 \\
2.58 \pm 1.38 \\
1.53 \pm 1.14^{d} \\
P<0.001\end{array}$ & $\begin{array}{l}0.068 \\
0.276 \\
0.785\end{array}$ \\
\hline$L^{*}$ value & $\begin{array}{l}\text { Low } \\
\text { High }\end{array}$ & $\begin{array}{l}122 \\
122\end{array}$ & $\begin{array}{l}2.20 \pm 1.42 \\
3.06 \pm 1.69 \\
p<0.001\end{array}$ & $\begin{array}{l}61 \\
61\end{array}$ & $\begin{array}{l}2.43 \pm 1.62 \\
3.37 \pm 1.88 \\
P=0.004\end{array}$ & $\begin{array}{l}61 \\
61\end{array}$ & $\begin{array}{l}2.05 \pm 1.22 \\
2.67 \pm 1.42 \\
P=0.011\end{array}$ & $\begin{array}{l}0.154 \\
0.023\end{array}$ \\
\hline Melanin index & $\begin{array}{l}\text { Low } \\
\text { High }\end{array}$ & $\begin{array}{l}122 \\
122\end{array}$ & $\begin{array}{l}3.20 \pm 1.79 \\
2.06 \pm 1.18 \\
P<0.001\end{array}$ & $\begin{array}{l}61 \\
61\end{array}$ & $\begin{array}{l}3.61 \pm 2.05 \\
2.19 \pm 1.18 \\
P<0.001\end{array}$ & $\begin{array}{l}61 \\
61\end{array}$ & $\begin{array}{l}2.70 \pm 1.41 \\
2.02 \pm 1.22 \\
p=0.005\end{array}$ & $\begin{array}{l}0.006 \\
0.445\end{array}$ \\
\hline
\end{tabular}

Notes: Mean \pm SD. ${ }^{a} \mathrm{p}$-value between high TP and low TP groups. ${ }^{b} \mathrm{p}<0.001 .{ }^{c} \mathrm{p}=0.002 .{ }^{d} \mathrm{p}=0.00 \mathrm{I}$ vs Skin type I.

score showed a partial correlation with skin color ( $\mathrm{L}^{*}$ value) and melanin index (control variable: age) at $\mathrm{R}=-0.434$ $(\mathrm{p}<0.001)$ and $\mathrm{R}=0.523(\mathrm{p}<0.001)$, respectively. Subjects with a high $L^{*}$ value, a lighter skin color and a lower melanin index had higher PS scores $(\mathrm{p}<0.001$ and $\mathrm{p}<0.001$, respectively, Table 3). The consumption of TPs suppressed the PS score in subjects with a light skin color (high $\mathrm{L}^{*}$ value) or low melanin index $(\mathrm{p}=0.023$ and 0.006 , respectively, Table 3).

The consumption of TPs from different sources and the relationship between TP sources and PS scores are shown in Table 4. The consumption of TPs in all subjects was $1225 \pm$ $827 \mathrm{mg} /$ day, and coffee and green tea, the top $2 \mathrm{TP}$ sources, greatly contributed to total consumption at $53 \%$ and $8 \%$, respectively. Daily TP consumption from all foods was 300 $\pm 203 \mathrm{mg}$ ( $25 \%$ of the total) but was not associated with the PS score. The intake of TPs from all beverages was $925 \pm$ $784 \mathrm{mg}$ ( $75 \%$ of the total), which showed a significant negative correlation against the PS score $(p<0.001)$. TPs from other beverages showed a negative association against the PS score; however, there were no beverage items other than coffee and green tea that associated with the PS score significantly. Subjects with a high consumption of TPs from coffee ( $\geq 400 \mathrm{mg} / \mathrm{day}$, corresponding to 1.5 cups of coffee) showed significantly lower PS scores than subjects with a low consumption of TPs from coffee ( $<<0.001$, Table 5). Green tea did not have as much of an impact as coffee but subjects with a high consumption of TPs from green tea ( $\geq 41 \mathrm{mg} /$ day, corresponding to a half cup of green tea) showed lower PS scores than subjects with a low

Table 4 Partial Correlations Between PS Scores and the Consumption of TPs from Different Sources of Food and Beverages

\begin{tabular}{|l|l|l|l|l|}
\hline Sources & TP Consumption (mg/day) & $\%$ Contribution & \multicolumn{2}{l|}{$\begin{array}{l}\text { TP Consumption vs PS } \\
\text { Score }\end{array}$} \\
\cline { 2 - 5 } & & & $R$ & R \\
\hline Cereals and noodles & & & 0.034 & 0.602 \\
Fruits and vegetables & $10.4 \pm 10.2$ & $1 \%$ & -0.024 & 0.709 \\
Other foods & $87.9 \pm 59.9$ & $7 \%$ & -0.024 & 0.708 \\
Total foods & $202 \pm 179$ & $17 \%$ & -0.027 & 0.680 \\
\hline Coffee & $300 \pm 203$ & $25 \%$ & -0.191 & 0.003 \\
Green tea & $655 \pm 703$ & $53 \%$ & -0.136 & 0.034 \\
Other beverages & $103 \pm 174$ & $8 \%$ & -0.144 & 0.024 \\
Total beverages & $167 \pm 152$ & $14 \%$ & -0.230 & $<0.001$ \\
\hline Total food and beverages & $925 \pm 784$ & $75 \%$ & $100 \%$ & -0.224 \\
All food and beverages except for coffee and green tea & $467 \pm 270$ & $38 \%$ & -0.101 & 0.115 \\
\hline
\end{tabular}

Note: Control variable: age 
Table 5 PS Scores and the Consumption of TPs in Groups of Subjects with High and/or Low Consumption of Coffee and Green Tea

\begin{tabular}{|c|c|c|c|c|c|c|c|c|c|c|}
\hline \multirow[t]{2}{*}{ Group } & & \multirow[t]{2}{*}{$\mathbf{n}$} & \multicolumn{2}{|l|}{ PS Score } & \multicolumn{2}{|c|}{ TPs from Coffee } & \multicolumn{2}{|c|}{ TPs from Green Tea } & \multicolumn{2}{|c|}{$\begin{array}{l}\text { TPs from All Foods } \\
\text { and Beverages }\end{array}$} \\
\hline & & & & p-value ${ }^{a}$ & $\mathrm{mg} /$ day & p-value ${ }^{a}$ & $\mathrm{mg} / \mathrm{day}$ & p-value ${ }^{a}$ & mg/day & p-value ${ }^{a}$ \\
\hline \multirow[t]{2}{*}{ Coffee } & Low & 118 & $3.01 \pm 1.79$ & & $108 \pm 114$ & & $84 \pm 134$ & & $639 \pm 357$ & \\
\hline & High & 126 & $2.28 \pm 1.36$ & $<0.001$ & $1166 \pm 634$ & $<0.001$ & $|2| \pm 203$ & 0.091 & $1774 \pm 763$ & $<0.001$ \\
\hline \multirow[t]{2}{*}{ Green tea } & Low & 118 & $2.85 \pm 1.79$ & & $611 \pm 679$ & & $13 \pm 14$ & & $1053 \pm 773$ & \\
\hline & High & 126 & $2.40 \pm 1.39$ & 0.029 & $701 \pm 727$ & 0.319 & $198 \pm 211$ & $<0.001$ & $1405 \pm 846$ & 0.001 \\
\hline Coffee (C) and & Group I (low in both) & 56 & $3.22 \pm 2.06$ & & $70 \pm 98$ & & $9 \pm 11$ & & $491 \pm 273$ & \\
\hline \multirow[t]{3}{*}{ Green tea $(\mathrm{GT})^{\mathrm{b}}$} & Group 2 (low C and high GT) & 62 & $2.81 \pm 1.49$ & 0.361 & $143 \pm 117$ & 0.719 & $151 \pm 157$ & $<0.001$ & $773 \pm 372$ & 0.027 \\
\hline & Group 3 (high C and low GT) & 62 & $2.43 \pm 1.21$ & 0.019 & $1157 \pm 572$ & $\mathrm{p}<0.001$ & $13 \pm 13$ & 0.998 & $1636 \pm 678$ & $<0.001$ \\
\hline & Group 4 (high in both) & 64 & $2.13 \pm 1.49$ & 0.001 & $1176 \pm 693$ & $p<0.001$ & $226 \pm 243$ & $<0.001$ & $1907 \pm 820$ & $<0.001$ \\
\hline
\end{tabular}

Notes: Mean \pm SD. ${ }^{a}$ Comparisons were made between low TP and high TP groups or vs Group I (low in both). ${ }^{b}$ ANOVA $p$-values were $p=0.001$ for PS Score and $p<0.001$ for TPs from coffee, TPs from green tea, and TPs from all foods and beverages.

consumption of TPs from green tea $(\mathrm{p}=0.029$, Table 5$)$. Four groups were created with different combinations of coffee and green tea consumption, where Group 3 (high in coffee and low in green tea) and Group 4 (both high in coffee and green tea) showed significantly lower PS scores than Group 1 (both low in coffee and green tea) $(\mathrm{p}=0.019$ and $\mathrm{p}=0.001$, respectively, Table 5).

\section{Discussion}

We conducted a cross-sectional survey of healthy middleaged Japanese women aged from 30 to 60 years $(n=244)$ to examine if there is a relationship between the consumption of TPs and the hyperpigmentation of facial skin. The results show that a higher consumption of TPs contributed to suppress skin hyperpigmentation measured using a VISIA ${ }^{\mathrm{TM}}$ facial image analyzer. The UV Pigmented Spot (PS) count and its ratio (the PS score divided by the PS count), which indicates the average area of hyperpigmented spots, were similarly suppressed by the consumption of TPs, suggesting that TPs suppressed both the number of pigmented spots and the area of pigmented spots. This study showed that not only coffee, the largest source of TP in the Japanese diet representing half of the total consumption of TPs, ${ }^{9}$ but also green tea, the second highest source of TPs, contributed to suppress hyperpigmentation. Subjects with a high consumption of TPs in both beverages showed the lowest PS scores. Our previous study showed that there are no seasonal changes in PS scores. ${ }^{10}$ In the present study, we combined two sets of crosssectional surveys recruiting subjects in the summer and in the winter, after confirming that both groups of subjects had similar PS scores and that TPs similarly suppressed their PS scores. This finding confirmed that the PS score is not influenced by the season and that the findings are reproducible; thus, the suppression of hyperpigmentation by the consumption of TPs was confirmed.

Facial hyperpigmentation can occur at any age depending on etiological factors but our previous study showed that its intensity increases in Japanese females from adolescence around 18 years of age and then gradually develops further in adults. ${ }^{10}$ Individual differences in PS scores were large but there were no trends in the distribution of PS score in each age segment between 30 and 60 years of age. We estimated the rate of hyperpigmented spot development (PS score/years after 18 years of age) and showed that the rate was suppressed by the consumption of TPs, which also meant that the suppression of hyperpigmentation was observed after adjusting for the age difference in subjects. Hyperpigmented spots, once they occur, are stable and the location and intensity of each hyperpigmented spot do not usually change within a few years. ${ }^{10}$ This study is a cross-over survey and the causal association of hyperpigmented spot development and the consumption of TPs can not be conclusively established, which is a limitation of this study. As a pilot trial, we conducted a follow-up survey using the same set of questionnaires and VISIA ${ }^{\mathrm{TM}}$ analyses in some subjects 2.5 years after this survey $(n=132,32-62$ years old). ${ }^{14,15}$ Visual analysis of UV photos showed that the area of existing pigmented spots slightly expanded in $61 \%$ of those subjects, but such small changes cannot be detected by VISIA $^{\mathrm{TM}}$ as the PS score. None of the subjects had developed new hyperpigmented spots in those 2.5 years. Lower scores of hyperpigmented spots remained in subjects who maintained high consumption of coffee TPs. A longitudinal study is required to determine a causal effect, and at least a 5- to 10year observation period would be required. 
This study evaluated how much of an influence the consumption of TPs has on the suppression of the PS score. We reconfirmed that the skin type is a significant influential factor in hyperpigmentation, and subjects with Skin Type III, who can efficiently produce melanin after UV exposure, were the most protected against skin hyperpigmentation. Subjects with higher consumption of TPs tended to have lower PS scores in each skin type, which suggests that the suppressive effect of TP consumption on hyperpigmentation is independent of the skin type. Dark skin color, which has a low $\mathrm{L}^{*}$ value and a higher melanin index, was also a suppressive factor for skin hyperpigmented spots. The skin type determines the ability to suntan after UV exposure, which is responsible for the efficacy of melanin production. Skin color and the melanin index show stable states of melanin pigment distribution that work as a protective factor for the skin against UV exposure. The response to sun exposure and the constitutive production level of melanin are different; however, skin color and the melanin index are correlated with the skin type, which influences hyperpigmentation. ${ }^{10}$ We showed in this study that those factors are not correlated with the consumption of TPs, which suggests that the consumption of TPs is an independent suppressive factor of skin hyperpigmentation.

Clinical observations of an abnormally early onset of solar lentigines in Xeroderma pigmentosum patients indicate that DNA repair defects result in DNA damage induced by solar UV light and cause severe hyperpigmentation spot development. ${ }^{16}$ Even in the healthy normal population, it is hypothesized that the development of hyperpigmented spots may also occur through gene mutations of keratinocytes and/or melanocytes following UV exposure for a few decades. Mutations in genes encoding stem cell factor, endothelin-1 and proopiomelanocortin in keratinocytes have been suggested to be responsible for the development of solar lentigines in healthy subjects. ${ }^{17,18}$ Mutagenesis via UV damage is due to the production of cyclobutane pyrimidine dimers (CPDs) in DNA strands by the absorption of UV and also by indirect effects of ROS. ${ }^{19}$ Recently, Premi et al. showed that CPDs are generated for more than $3 \mathrm{hrs}$ after exposure to UVA, a major component of the radiation in sunlight, and not only ROS but also reactive nitrogen species play roles in the UV-associated DNA damage. ${ }^{20}$ Antioxidants, such as green tea polyphenol, show photoprotective effects to decrease DNA damage and have anti-carcinogenic and anti-inflammation properties. ${ }^{4}$ The oral intake of green tea polyphenols at a high dose of $1.4 \mathrm{~g}$ for 12 weeks was shown to have protective effects against UVinduced erythema and structural characteristics of the skin such as elasticity, and skin density was maintained after UV exposure in humans. ${ }^{21}$ However, the underlying mechanism by which polyphenols contribute to suppress hyperpigmentation is still not clear, especially for coffee polyphenols. Coffee and green tea deliver more than half of TPs consumed in the Japanese diet as shown in this study and in previous studies.' Polyphenols are a major source of antioxidants and foods rich in polyphenols, such as coffee and tea, have protective effects against oxidative-stress-related diseases such as cardiovascular diseases, type 2 diabetes and some cancers. ${ }^{22}$ At least one-third of polyphenols from coffee and green tea are absorbed through the intestines and appear in the circulation, ${ }^{23,24}$ and oxidative damage to macromolecules including DNA has been shown to be suppressed by coffee and green tea consumption in humans. ${ }^{25,26}$ These considerations, which may contribute to reduce oxidative stress in humans, may play a role in the suppression of hyperpigmentation shown in this study.

\section{Conclusion}

The consumption of TPs may be beneficial for reducing photoaging of the skin, and not only coffee but also green tea contribute to suppress skin hyperpigmentation through providing large amounts of TPs in the Japanese diet. Further study is required to understand the underlying mechanism(s) of the suppressive effect of TPs on hyperpigmentation and studying younger subjects could be helpful for further understanding of that process.

\section{Acknowledgment}

We are grateful to the volunteers for participating in the survey.

\section{Disclosure}

YF is affiliated with Wellness Communications Section, Nestlé Japan Ltd., Tokyo, Japan. YT is affiliated with Inary Corp., Tokyo, Japan. The authors report no other conflicts of interest in this work.

\section{References}

1. Richard S, de Rigal J, de Lacharriere O, Berardesca E, Leveque JL. Noninvasive measurement of the effect of lifetime exposure to the sun on the aged skin. Photodermatol Photoimmunol Photomed. 1994;10 (4):164-169.

2. Brand RM, Wipf P, Durham A, Epperly MW, Greenberger JS, Falo LD Jr. Targeting mitochondrial oxidative stress to mitigate UV-induced skin damage. Front Pharmacol. 2018;9:920. doi:10.3389/fphar.2018.00920

3. Ichihashi $M$, Ando $H$. The maximal cumulative solar UVB dose allowed to maintain healthy and young skin and prevent premature photoaging. Exp Dermatol. 2014;23(Suppl 1):43-46. doi:10.1111/ exd. 12393 
4. Parrado C, Philips N, Gilaberte Y, Juarranz A, González S. Oral photoprotection: effective agents and potential candidates. Front Med. 2018;5:188. doi:10.3389/fmed.2018.00188

5. Hillebrand GG, Miyamoto K, Schnell B, Ichihashi M, Shinkura R, Akiba S. Quantitative evaluation of skin condition in an epidemiological survey of females living in northern versus southern Japan. J Dermatol Sci. 2001;27(Suppl 1):S42-S52. doi:10.1016/s0923-1811(01)00118-9

6. Fukushima Y, Takahashi Y, Hori Y, et al. Skin photoprotection and consumption of coffee and polyphenols in healthy middle-aged Japanese females. Int J Dermatol. 2015;54(4):410-418. doi:10.1111/ijd.12399

7. Goldsberry A, Hanke CW, Hanke KE. VISIA system: a possible tool in the cosmetic practice. J Drugs Dermatol. 2014;13(11): 1312-1314.

8. Fukushima Y, Ohie T, Yonekawa Y, et al. Coffee and green tea as a large source of antioxidant polyphenols in the Japanese population. J Agric Food Chem. 2009;57(4):1253-1259. doi:10.1021/jf802418j

9. Fukushima Y, Tashiro T, Kumagai A, et al. Coffee and beverages are the major contributors to polyphenol consumption from food and beverages in Japanese middle-aged women. J Nutr Sci. 2014;3:e48. doi:10.1017/jns.2014.19

10. Takahashi Y, Fukushima Y, Kondo K, Ichihashi M. Facial skin photo-aging and development of hyperpigmented spots from children to middle-aged Japanese women. Skin Res Technol. 2017;23(4):613-618. doi:10.1111/srt.12380

11. Kawada A. UVB-induced erythema, delayed tanning, and UVA-induced immediate tanning in Japanese skin. Photodermatol. 1986;3(6):327-333.

12. Kobayashi S, Murakami K, Sasaki S, et al. Comparison of relative validity of food group intakes estimated by comprehensive and brief-type self-administered diet history questionnaires against 16 d dietary records in Japanese adults. Public Health Nutr. 2011;14 (7):1200-1211. doi:10.1017/S1368980011000504

13. Ainsworth BE, Haskell WL, Whitt MC, et al. Compendium of Physical Activities: an update of activity codes and MET intensities. Med Sci Sports Exerc. 2000;32(Suppl):S498-S516. doi:10.1097/00005768200009001-00009

14. Fukushima Y, Takahashi Y, Kishimoto Y, et al. Skin photoprotection and consumption of coffee and polyphenols in healthy Japanese females. Oral presentation at the 27th International Conference on Polyphenols. September 5; 2014; Nagoya.

15. Fukushima Y, Takahashi Y, Kishimoto Y, et al. Photo-aging of skin and consumption of coffee and polyphenol in healthy Japanese females. Poster presented at the 12th Asian Contress of Nutrition; May 16; 2015; Yokohama.
16. Cleaver JE. Defective repair replication of DNA in xeroderma pigmentosum. Nature. 1968;218(5142):652-656. doi:10.1038/218652a0

17. Kadono S, Manaka I, Kawashima M, Kobayashi T, Imokawa G. The role of the epidermal endothelin cascade in the hyperpigmentation mechanism of lentigo senilis. $J$ Invest Dermatol. 2001;116 (4):571-577. doi:10.1046/j.1523-1747.2001.01296.x

18. Imokawa G. Autocrine and paracrine regulation of melanocytes in human skin and in pigmentary disorders. Pigment Cell Res. 2004;17 (2):96-110. doi:10.1111/j.1600-0749.2003.00126.x

19. Ahmed NU, Ueda M, Nikaido O, Osawa T, Ichihashi M. High levels of 8-hydroxy-2-deoxyguanosine appear in normal human epidermis after a single dose of ultraviolet irradiation. Br J Dermatol. 1999;140 (2):226-231. doi:10.1111/j.1365-2133.1999.02653.x

20. Premi S, Wallisch S, Mano CM, et al. Photochemistry. Chemiexcitation of melanin derivatives induces DNA photoproducts long after UV exposure. Science. 2015;347(6224):842-847. doi:10.1126/science.1256022

21. Heinrich U, Moore CE, De Spirt S, Tronnier H, Stahl W. Green tea polyphenols provide photoprotection, increase microcirculation, and modulate skin properties of women. J Nutr. 2011;141(6):1202-1208. doi:10.3945/jn.110.136465

22. Grosso G, Godos J, Galvano F, Giovannucci EL. Coffee, caffeine, and health outcomes: an umbrella review. Annu Rev Nutr. 2017;37:131-156. doi:10.1146/annurev-nutr-071816-064941

23. Renouf M, Guy P, Marmet C, et al. Plasma appearance and correlation between coffee and green tea metabolites in human subjects. $\mathrm{Br}$ J Nutr. 2010;104(11):1635-1640. doi:10.1017/S0007114510002709

24. Williamson G, Clifford MN. Role of the small intestine, colon and microbiota in determining the metabolic fate of polyphenols. Biochem Pharmacol. 2017;139:24-39. doi:10.1016/j.bcp.2017.03.012

25. Hoelzl C, Knasmüller S, Wagner KH, et al. Instant coffee with high chlorogenic acid levels protects humans against oxidative damage of macromolecules. Mol Nutr Food Res. 2010;54(12):1722-1733. doi:10.1002/mnfr.201000048

26. Sakata R, Nakamura T, Torimura T, Ueno T, Sata M. Green tea with high-density catechins improves liver function and fat infiltration in non-alcoholic fatty liver disease (NAFLD) patients: a double-blind placebo-controlled study. Int J Mol Med. 2013;32(5):989-994. doi:10.3892/ijmm.2013.1503
Clinical, Cosmetic and Investigational Dermatology is an international, peer-reviewed, open access, online journal that focuses on the latest clinical and experimental research in all aspects of skin disease and cosmetic interventions. This journal is indexed on CAS.
The manuscript management system is completely online and includes a very quick and fair peer-review system, which is all easy to use. Visit http://www.dovepress.com/testimonials.php to read real quotes from published authors. 